\title{
Lithium ion car batteries: Present analysis and future predictions
}

\author{
James Arambarri ${ }^{1}$, James Hayden ${ }^{1}$, Mostafa Elkurdy ${ }^{1}$, Bryan Meyers ${ }^{1}$, Ziad Salem Abu Hamatteh ${ }^{2^{\dagger}}$, \\ Bassim Abbassi ${ }^{1}$, Waid Omar ${ }^{2}$ \\ ${ }^{1}$ School of Engineering, University of Guelph, Guelph, Ontario, Canada \\ ${ }^{2}$ Faculty of Engineering Technology, Al-Balqa Applied University, Amman (11134), Jordan
}

\begin{abstract}
Electric vehicles (EVs) are spreading rapidly and many counties are promoting hybrid and fully EVs through legislation. Therefore, an increasing amount of lithium ion batteries will reach the end of their usable life and will require effective and sustainable end-of-life management plan which include landfill disposal or incineration. The current research focuses on more sustainable methods such as remanufacturing, reuse and recycling in order to prepare for future battery compositions and provide insights to the need recycling methods to be developed to handle large amounts of batteries sustainably in the near future. The two most prominent material recovery techniques are hydrometallurgy and pyrometallurgy which are explored and assessed on their relative effectiveness, sustainability, and feasibility. Hydrometallurgy is a superior recycling method due to high material recovery and purity, very low emissions, high prevalence of chemical reuse and implementation of environmentally sustainable compounds. Expanding recycling technologies globally should take the research and technologies pioneered by Umicore to establish a sustainable recycling program for end-of-life EVs batteries. Emerging battery technology of Telsa show the most effective designs for high performance batteries includes the use of silicon which is expected to increase capacity of batteries in the future.
\end{abstract}

Keywords: EV batteries, Hydrometallurgy and pyrometallurgy, Life cycle analysis, Performance, Recycling, Sustainability

\section{Introduction}

\subsection{Subject Background}

Global greenhouse gas (GHG) emission rates have sky rocketed over the last several decades, causing a plethora of different issues, most of which pertain to air quality. Due to increasingly poor air quality in big cities around the world, various countries have begun to set out plans to phase out or completely ban the production and use of combustion-only vehicles. The alternative means producing and using hybrid-electric vehicles (HEVs) or fully electric vehicles (EVs). HEVs use Nickel Metal Hydride (NiMH) batteries and EVs utilize Lithium-ion batteries (LIBs), both of which represent power sources that are used to propel the vehicle. Of the two alternatives, EVs are the preferred choice with regards to impacts on GHG emissions, as they produce zero emissions once they are obtained by the consumer. The primary hazard in LIBs is the electrolyte, the media that the lithium ions move through when the battery is charged or discharged. This often contains an organic solvent that is corrosive and flammable. Under wrong conditions of handling, storage, and end-of-life processing, corrosion, fire, and explosion are the associated risks.

\subsection{Problem Statement}

As HEVs and more importantly EVs become more popular and numerous on city streets, a problem then arises with disposing of the batteries, once they have reached the end of their usable life in a vehicle. All of the EVs that are being produced today use LIBs as their form of power, as LIBs in particular have a very high energy density, require very low maintenance over their life and do not require any sort of priming, prior to use [1]. The underlying issue is that LIB recycling techniques are very limited and still exist in their infant phases, due to the fact that these batteries have only seen widespread use in vehicles for under a decade. Without any recycling taking place, new raw materials will continually be required to meet production demands, which places extensive stress on material sources and
This is an Open Access article distributed under the terms of the Creative Commons Attribution Non-Commercial License (http://creativecommons.org/licenses/by-nc/3.0/) which permits unrestricted non-commercial use, distribution, and reproduction in any medium, provided the original work is properly cited.

Copyright (C) 2019 Korean Society of Environmental Engineers
Received November 1, 2018 Accepted January 16, 2019

${ }^{\dagger}$ Corresponding author

Email: hamatteh@bau.edu.jo; drabuhamatteh@yahoo.com Tel: +962-777-484-772, +962-799-059-035 Fax: +962-6-4790350 ORCID: 0000-0003-0929-1011 
creates colossal amounts of GHG emissions through production and transportation related activities. The elemental question then becomes: to what extent is the production of EVs actually environmentally friendly and what should be expected of the LIB recycling industry in the future, in order to maximize the sustainability of EVs.

\subsection{Motivation Justification}

The motivation for producing this report is the lack of current widespread LIB recycling practices and the necessity for companies to develop sustainable recycling techniques in order to counteract raw material shortages and to further mitigate GHG emissions. For this reason, current recycling processes will be analyzed and their advantages/limitations will be compared. Companies leading the way in LIB recycling will be brought to light and their predictions for the future of EVs will be evaluated and discussed.

\section{Methodology}

The widespread use of LIBs in EVs has only become significant in the last decade; therefore data collection must be performed with care in order to obtain relevant, credible information. Several criteria that were considered while searching for data include using sources published after the year 2010 when possible, using sources that are peer reviewed and sources that come from accredited journals/magazines, to prevent the use of false or flawed data. Over 120 studies were analyzed while obtaining data, but only 43 studies/papers were deemed credible enough to be utilized in this report. A majority of the final sources used to compose this report come from scientific magazines, university publications or from company websites who deal specifically with LIBs.

\section{Growth in the Electric Vehicle Industry}

As previously mentioned, exponentially poorer air quality in large cities is pushing countries towards the phasing out or complete ban of fully combustion engine vehicles. This is being done with the hopes that the transition to HEVs and EVs will mitigate GHG emissions and improve the overall air quality. Countries such as Norway, India, the Netherlands and Germany have all claimed that they plan to ban the sale of combustion engine vehicles within the next $12 \mathrm{y}$ [2]. Currently, only $0.2 \%$ of the vehicles driving on the streets globally are EVs, which correlates to a value of approximately 2 million EVs [3]. However, this figure is expected to increase drastically with the implementation of the combustion engine ban in forthcoming years. Recent studies have shown new registrations of EVs rose 70\% between 2014 and 2015, with approximately 0.55 million EVs sold globally in 2015 [4].

Fig. 1 represents a forecast of predicted car sales numbers, comparing combustion engines, EVs and HEVs in the upcoming year. It can be seen that both EV and HEVs sales are expected to

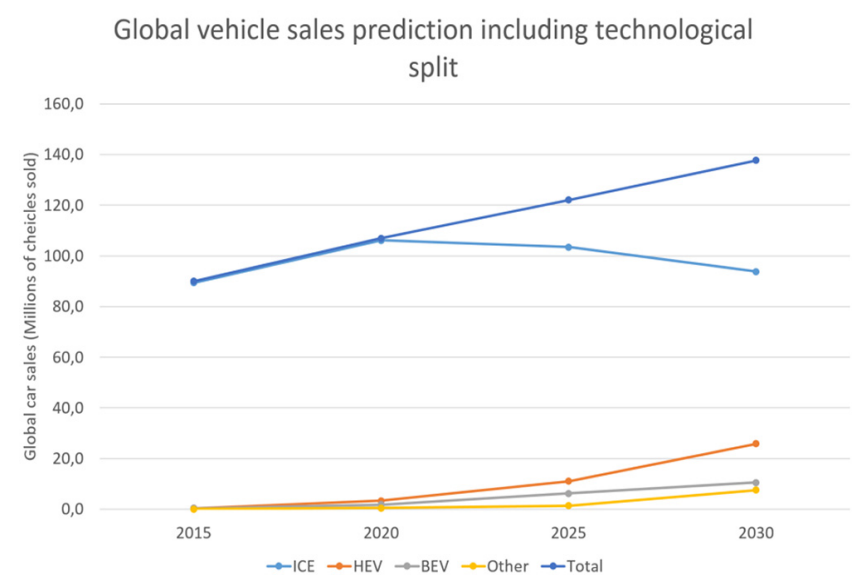

Fig. 1. Forecast of the predicted car sale numbers of various engine types by 2030 [5].

increase by 2030 as where combustion engines are predicted to drop by roughly 10 million units sold.

In order to achieve forceful goals such as banning the production of combustion engine vehicles, various countries have implemented incentives with the goal of encouraging consumers to make the transition away from combustion engines. The same countries who have executed future bans on combustion engine vehicles provide an assortment of incentive to buy EVs, such as: cost reductions off of the MSRP of new EVs, annual road tax exclusion, tax deductions along with others such as EV and HEVs only lanes on highways and parking lots in cities. The international Energy Agency's EV initiative which aims to achieve 20 million EVs on the road by 2020 has 16 member countries. This reflects the growing commitment to EVs as a tool to combat pollution and climate change on a global scale [4].

\section{Raw Materials}

One of the foundational concepts in Micro-economics is demarcated through the principles of the supply and demand relationship. Theoretically speaking, as demand for a particular good increases over the long run, the price for that good should in turn decrease to a certain extent. Only goods described as inelastic would defy this principle. As established earlier in the report, although combustion engine vehicles represent over 99\% of the total vehicles on the global roads, by 2030 this is expected to drop to just $68.1 \%$ [5]. Despite a seemingly obvious long-term dominance of the EV in the transportation sector, their expected rise has been slow as developers struggle to deal with a limited battery supply chain and a large price disparity of production when compared to their combustion rivals [6]

A new study published by McKinsey and Company reported that the mass manufacturing of EVs will not become entirely profitable until at least 2020-2025 [7]. This is mainly to do with the fact that while electric vehicle prices are falling dramatically, battery prices have surged in recent years. This can be explained by a simple supply-side delay in the sudden increase in demand 
for LIBs as the supply for the raw materials has remained relatively the same.

Although LIBs are globally considered to be the future foundation for transportation, they struggle to reach price parity with lead-acid batteries due to their limited supply side materials. This section will breakdown the raw materials involved in the production of LIBs and attempt to explain the economic and industrial trends we are witnessing today and expect to see over the coming decades.

\subsection{Li-ion Battery Composition}

LIBs have risen immensely in popularity in part due to increasing awareness towards transitioning to lower carbon economies. However, they have become so favorable from a technical standpoint due to their high energy capacity, power density, and relatively lengthy lifetime [8]. The main components of the LIB can essentially be broken down from a materials standpoint into three main components: the anode, cathode, and electrolyte. An in-depth description behind these components reveals many insights into the economies of EV and their LIBs

\subsubsection{Anode}

The diversity within the types of anodes used in LIBs is extremely subdued due to the market dominance of graphite. Graphite was first commercialized $20 \mathrm{y}$ ago after the development of the carbon anode and due to its high natural abundance, low cost, and moderate energy density it quickly became the primary anode material in LIBs [9].

Although graphite remains by far the most used material commercially available for battery anodes, an alternate material that has garnered recent attention has been Lithium Titanium Oxide (LTO). While the LTO anode composed in part by Titanium carries a much higher cost in production, the LTO anode has developed some competitive advantages such as its high volumetric capacity and longer life cycle [9]. The LTO anode exhibited capacity retention of $95 \%$ after 30,000 that was experimentally achieved during a high-rate cycle life test which suggests that the capacity fading rate of LTO systems are inherently dependent on the cathode potential during storage [10]. Furthermore, LTO is also considered to be a safer anode since it does not have the potential to form Lithium dendrite; a compound that can contribute to spontaneous combustion in LIBs [9].

While the LTO represents a potential future competitor for graphite, the already heightened costs of the battery itself will likely discourage both industry and Governments from investing. Instead, composition modifications of the graphite anode have been the focus of industry efforts: namely the Silicon Oxide anode.

One of the most important properties when discussing anode materials is the extent of volume change that occurs due to the migration of ions that causes the cyclic expansion and contraction of the electrodes. Graphite has a complex carbon crystal structure allowing it to hold up to 372 (miliamp h/g carbon) while experiencing a volume increase of around $10 \%$ when fully lithiated. Conversely, Silicon has the capability of holding significantly more Li-ions with a theoretical capacity of 4,200 (milliamp h/g carbon), however, it has been found to swell up to $300 \%$ [11, 12]. Additionally, the long-term expansion and contraction

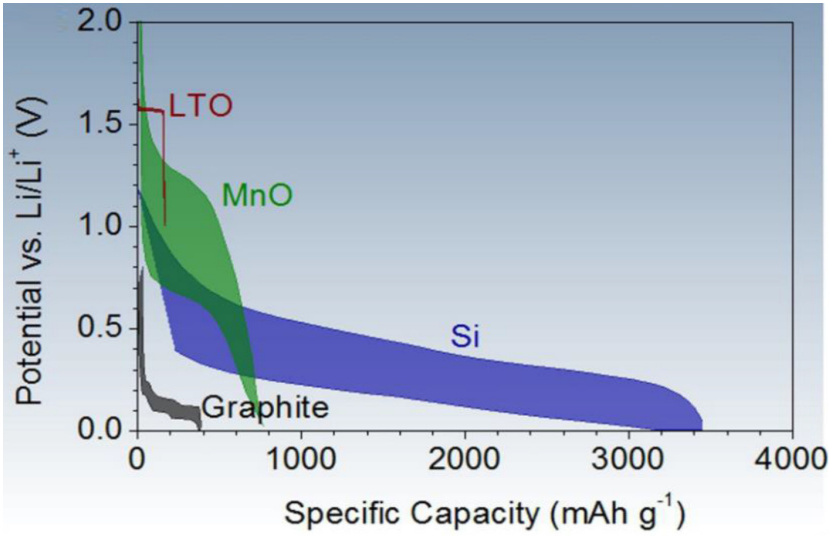

Fig. 2. Anode intercalation material potential voltage and specific capacity comparison [9].

of the electrodes has been found to lead to crack initiation and fracturing of particles which ultimately reduce the lifetime of the battery. These experimental phenomena may be discouraging many industry players from investing in Silicon-Graphite anodes and to instead stick with the most established and cost-effective anode material: Graphite. These material properties highlight the difficulty behind incorporating advantageous properties of alternative anodes such as Silicon into LIBs.

Fig. 2 highlights that Silicon has an extremely high potential specific capacity potential in LIBs and offer improvements behind potential voltage as well. Furthermore, HF acid is a by-product of water and Silicon particles and after continuous cycling the polymer matrix and thin elastomer membrane gradually break down leading to a breakdown in capacity and functionality [13].

While Silicon-Graphite anodes are not commonly utilized in industry that has not prevented companies such as Tesla from realizing its advantages as they have been gradually increasing the Silicon content in their EV anodes [11]. In reality, the percent composition of Silicon in commercially available Silicon Oxide anodes remains significantly low compared to Graphite.

\subsubsection{Cathode}

The Cathode is one of the most selective materials considered during LIB development. There exists a plethora of commercially tested cathode compositions that should be chosen based on their type of application. The main categories considered are: energy density, power density, cost and lifetime. It is important to define the difference between the first two categories: Energy density defines the batteries capacity by weight $(\mathrm{Wh} / \mathrm{kg}$ ) whereas power density describes the instantaneous output of energy based on its volume [14]. The table below has been developed comparing the previous mentioned parameters along with a variety of other key technical aspects in the Cathode.

Table 1 demonstrates that there isn't one standout cathode composition that dominates the global markets. Depending on the application, a producer may want to maximize average specific capacity over average voltage. For example, NCA cathodes are frequently used in electric train batteries as they have the largest average specific capacity standing at $200(\mathrm{mAh} / \mathrm{g})$. These numbers can be explained in part from the fact that electric train batteries 


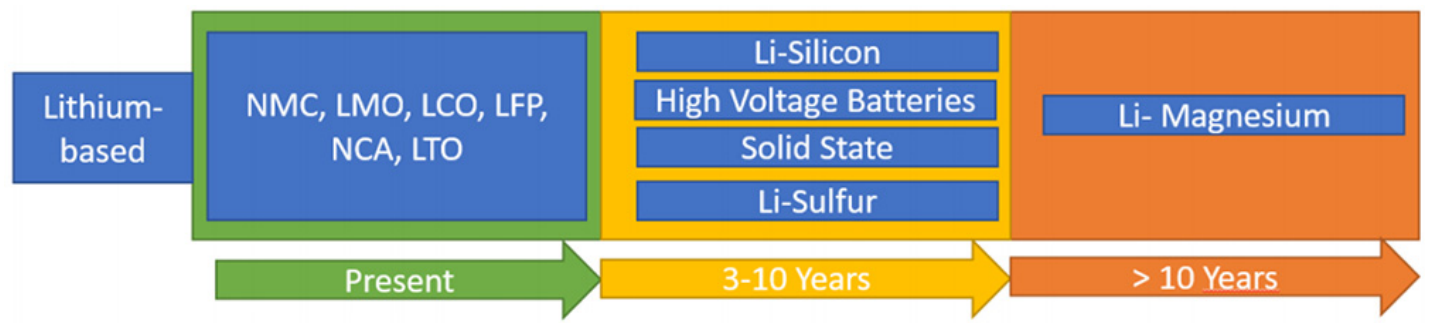

Fig. 3. Predicted dominating LIB types over time [5].

Table 1. Cathode Composition Comparisons [9]

\begin{tabular}{|c|c|c|c|c|c|}
\hline Categories & LCO & LNO & LMO & NMC & NCA \\
\hline Chemical structure & $\mathrm{LiCoO}_{2}$ & $\mathrm{LiNiO}_{2}$ & $\mathrm{LiMnO}_{2}$ & $\mathrm{LiNiMOCoO}_{2}$ & $\mathrm{LiNiCoAlO}_{2}$ \\
\hline Max spec. capacity (mAh/g) & 274 & 275 & 285 & 280 & 279 \\
\hline Average spec. capacity $(\mathrm{mAh} / \mathrm{g})$ & 145 & 150 & 140 & 170 & 200 \\
\hline $\begin{array}{l}\text { Typical volumetric capacity } \\
\left(\mathrm{mAh} / \mathrm{cm}^{3}\right)\end{array}$ & 550 & 1,280 & 1,148 & 600 & 700 \\
\hline $\begin{array}{l}\text { Theoretical volumetric capacity } \\
\left(\mathrm{mAh} / \mathrm{cm}^{3}\right)\end{array}$ & 1,363 & 1,280 & 1,148 & 1,333 & 1,284 \\
\hline Average voltage $\left(\mathrm{Li} / \mathrm{Li}^{+}\right)$ & 3.8 & 3.8 & 3.3 & 3.7 & 3.6 \\
\hline \# Cycle & $500-1,000$ & $300-700$ & $300-700$ & $1,000-2,000$ & 500 \\
\hline State of development & $\begin{array}{l}\text { commercially } \\
\text { stable }\end{array}$ & $\begin{array}{l}\text { commercially } \\
\text { stable }\end{array}$ & $\begin{array}{l}\text { commercially } \\
\text { stable }\end{array}$ & $\begin{array}{c}\text { newly } \\
\text { commercialized }\end{array}$ & $\begin{array}{c}\text { newly } \\
\text { commercialized }\end{array}$ \\
\hline Anode & graphite anode & graphite anode & $\begin{array}{l}\text { power tools, } \\
\text { electric train }\end{array}$ & $\begin{array}{l}\text { graphite anode / } \\
\text { silicon-graphite }\end{array}$ & graphite anode \\
\hline Commercial application & Apple iphone & $\begin{array}{l}\text { power tools, } \\
\text { medical devices, } \\
\text { electric train }\end{array}$ & Nissan leaf & $\begin{array}{c}\text { EVs, medical } \\
\text { devices, industrial }\end{array}$ & $\begin{array}{l}\text { electric train, } \\
\text { industrial }\end{array}$ \\
\hline
\end{tabular}

are designed with trip distance (capacity) being a priority as opposed to power density or lifetime. Conversely, cathode compositions employed in simpler devices such as cell phones and laptops tend to focus on elements such as volumetric capacity as they are designed to run for at least one day.

An additional way of analyzing the effectiveness of the varying cathodes is through cradle-to-gate analysis of the energy consumption, GHG emission and $\mathrm{SO}_{\mathrm{x}}$ production associated with each of the cathodes. Dunn et al. [15] use Argonne's GHG, Regulated Emissions, and Energy use in Transportation (GREET) to investigate the energy and emissions intensity of cathode preparation [15]. LCO cathodes appear to require the most energy consumption for production in both methods analyzed in the article (solid state and hydrothermal).

Moving forward, battery chemistry is increasingly being driven through innovation and a rise in demand for electric cars. Fierce competition between LIB producers will continue as the market is still in its infancy stage and significant improvements in terms of energy density, power density as well as the lifetime of the battery are expected to increase markedly. The batteries in use today are expected to be strikingly different in the upcoming decades as the industry begins to takeoff.

Fig. 3 demonstrates that batteries are constantly changing as our needs change and develop in different ways. The batteries of today are expected to be phased out by the end of the decade as new innovations within LIB such as the upcoming development of the Li-Mg LIB which is predicted to have significantly better properties compared to modern day LIB.

\subsubsection{Electrolyte}

The electrolyte is a medium that exists inside the battery that serves an extremely important function in terms of acting as the conveyance system for Li-ions to pass back and forth between the cathode and anode. The transfer of Li-ions occurs when the battery is discharging (ions travelling from anode to cathode) and when it is charging (ions travelling from cathode to anode), thus the more efficiently that the ions can travel, the better the battery will perform. The electrolyte is regarded as a substantial safety concern, as it must be able to withstand high temperatures and voltages throughout the entirety of the batteries useful life, without reacting unfavorably [16]. Typically, LIB manufacturers use various types of liquid electrolytes, which differ in energy consumption, power output, safety features and cost $[17,18]$. Liquid based electrolytes commonly consist of organic carbons including Propylene Carbonate, Ethylene Carbonate and Di-Methyl Carbonate [19]. Although readily used in most EV's today, liquid based electrolytes pose various safety risks, including the formation of hydrofluoric acid caused by electrolyte fluid 
leaking from the battery and reacting with air. Additionally, the potential for spontaneous combustion is significantly higher when the internal battery temperatures become too high [19]. Due to the aforementioned safety concerns, companies are pushing towards new, safer technology, in the form of solid state electrolytes. Solid state electrolytes offer many advantages over their liquid counterparts. The main benefits include: higher energy storage and power capacity, resistance to dendrite formation, chemical stability over a wider voltage range and no risk of spontaneous combustion or explosions [20]. Moreover, solid state electrolytes allow for LIBs to become smaller and more compact, while maintaining the same storage capacity and power output [20]. A LIB using a liquid electrolyte will have limitations with regards to how small it can be constructed, as a reduction in electrode size in this case would result in a loss of power output.

\subsubsection{Separator}

The separator in an LIB is used to encapsulate the electrolyte inside the battery itself. It is a crucial LIB component, as it must facilitate ionic conductivity while preventing direct contact between the anode and cathode [21,22]. Generally comprised of polyethylene, the separator has no conductivity of its own, rather, it is used to essentially absorb and house the liquid electrolyte [23]. As the separator will be in constant contact with the anode and cathode simultaneously, the Li-ions are able to traverse through the electrolyte inside the separator to ultimately make the battery charge and discharge. Separators are designed to have pores that match the size of Li-ions, so that they can transfer through efficiently. Typically, these pores are 20-25 mm [23]. As mentioned above, the separator acts as a physical barrier between the anode and cathode which prevents them from ever coming in contact. This is critical to battery function, as contact between the anode and cathode could cause a short circuit, resulting in battery failure [24]. A short circuit in a LIB could result in the battery catching fire, so it is essential that the separator exits the production line, free of flaws or defects.

\subsubsection{Future pricing}

Companies such as Tesla have set directives to create a closed-loop supply system; in their case within North America. In order to do this, they will have to identify more Li sources and to ensure the opening of upcoming large scale manufacturing plants such as the Gigafactory run smoothly. Tesla recently announced an agreement with Pure Energy Minerals for rights to a guaranteed Li supply from Silver Creek mine in Nevada, hours away from the planned Gigafactory [25]. While initiatives such as the arrangement at Silver Peak mine in Nevada are coming to the forefront, it is important to note that Li comprises only 4\% [26] of the modern Li battery electrode. It consequently only contributes a limited amount to recent rising battery prices. There are many other elements of the LIB that require a more diversified supply chain. $65 \%$ of all Cobalt mined in the world originates from the Democratic Republic of Congo (DRC), a country currently struggling with corporate corruption and political strife [27]. Another common cathode material, Manganese, was subject to a sudden $50 \%$ price increase in 2015 after the government banned the export of the metal.
These are but a few examples describing the complex yet limited supply chain behind LIBs but offer a valuable insight and potential explanation towards rising EV battery costs. Furthermore, it remains a clear challenge for the LIB industry to develop a cost effective battery that does not have a large overall negative impact on the cost of the EV. If the industry wants to achieve price parity with combustion engine vehicles, they must find a way to diversify the supply chain in order to address rising battery material costs.

\section{Global Legislation}

The world as a whole has failed to address the expected monumental rise in waste LIB and the majority of countries in the world lack the laws and regulations to integrate responsible and sustainable disposal and recycling methods. Developed countries are the largest producers of LIB waste in the world and the failure to enforce producer extended responsibility or to pass disposal legislation has exasperated the problem for the future. Moving forward, many researchers insist the best way to manage these shortcomings is to develop an integrated system that takes into account all components involved in the product including consumers, producers, regulators, Industry Stewards, and waste processors [28].

As it stands, the European Union has made the biggest moves towards establishing a new classification of waste for LIB and to regulate their recycling and disposal practices. As of 2019, LIB will be classified as Hazardous Waste which will increase the standards behind their collection and disposal and increase the incentives for recycling firms who will be taking on more second hand products. While nations such as in the EU are recently passing legislation, other developed nations such as Canada and the US appear to be falling behind. According to the US government, LIB's are technically classified as safe for landfill disposal [29]. While lithium is extremely toxic, the developed LIB is not considered to be. However, land filling and incinerating these products is an immense waste of resources. The lead-acid battery achieved outstanding recycling numbers standing at over 99\% in North America. Governments should be pressed to emulate this success with the LIB considering that these batteries contain more recoverable materials and a more limited supply chain for which to produce the batteries. That being said, material recovery remains underdeveloped as new technology enters the market and a lack of established industry leaders has limited the potential for growth and application.

\section{Material Recovery}

The anticipated high collection rate in the future of the LIB industry will require effective post-vehicle use processing. Due to the current initiatives in place, and the relatively long life of the EV battery (anticipated 8-10 y for most models [30]), the focus on reprocessing LIBs is only expected to grow. LIBs in EVs are considered ineffective for vehicle use once the storage capacity of the 
battery drops below $70-80 \%$ to maintain the safety in operation and obligatory road haul [31]. Processing can include remanufacturing or repair, reuse for other purposes, and eventually recycling for the recovery of the valuable raw materials.

A single LIB consists of many cells with numerous groups, often around 100 cells total. Each of these cells can hold charge and supply power. The required replacement of the LIB is often a results of only a few of these many cells malfunctioning, and thus the storage and output of the remaining cells can still be sufficient supply for other applications. A study was conducted by the Mineta National Transit Research Consortium using a Long-Range Energy Alternatives Planning system (LEAP) model to predict how the forecasted volume of EV batteries anticipated can be dealt with [30]. The model results consider $85 \%$ of the batteries reusable in varying application, while only the remaining $15 \%$ will be damaged beyond repair and require recycling.

\subsection{Reuse}

A significant strategy to reduce the cost, environmental impacts, and labor disputes associated with manufacturing EV batteries is to integrate the use of remanufactured vehicle batteries over the use new batteries. This can cut cost because most cells in the battery are often still fully operational, and only a few cells need to be remanufactured for the battery to function at the required capacity. The current cost for a new Chevrolet Volt battery is $\$ 10,000$, while the estimated cost of the same battery remanufactured is $\$ 2,500$ [30]. This is based on a conservative estimate of $10 \%$ of the battery requiring replacement. Based on the Mineta National Transit Research Consortium study, a cost-benefit analysis was constructed and supports the economic viability of Li-ion battery remanufacturing. The study showed that even with a high initial investment to create a remanufacturing plant, remanufacturing was able to reduce LIB costs by approximately $40 \%$ when compared to creating the battery from raw material.

In addition to reuse in EVs, LIBs should be considered for other secondary-life uses. However, the difficulty with reuse for other applications is the required analysis and evaluation of the methodology involved with preparing the battery for its new use, as well as the cost involved. For example, EV batteries can be used for energy storage in residential applications. This can be useful for residents to save money over time by storing power in off-peak hours [32]. Other use of EV batteries that found its way in residential application is the solar energy systems [33]. Homes currently use batteries for this functionality, but using second life EV batteries can be much cheaper.

Other major options considered for implementing secondary uses of these batteries involve use at power generation plants for energy storage. A study conducted by Navigant Research analyses the revenue generated by the reuse of EV batteries in EVs as well as for energy storage in solar and wind power generation plants. This study found that the LIB repurposing industry will grow from $\$ 16$ million today to becoming a $\$ 3$ billion industry by $2035[32,34]$. Additionally, a study conducted to analyze the feasibility of reuse and recycling EV LIBs in the state of California analyzed the energy consumption and GHG emissions associated with using EV batteries for energy storage for wind and solar energy plants [33, 35]. The study considers three cases for the growth of EV battery disposal: fast, base case, and slow. Mostly base case conditions were analyzed, and projected a 7 $\mathrm{MtCO}_{2} \mathrm{e} / \mathrm{y}$ reduction by 2050 , which is around $1.5 \%$ of current total California emissions. It is important to note that this study is based on optimal transportation of batteries to a country that has the highest combined energy production of wind and solar energy. In addition, the variation between the first and second life storage capacity thresholds can skew these results. A relatively conservative estimate of $70 \%$ for the base case would provide GHG emission reduction when compared to natural gas energy production, while a $10 \%$ shift could drastically change the results $[33,35]$. No environmental limitations have been traces through our investigation for the reuse of LIB. However, LIB are potential sources of hazardous metal pollutants in the environment. These metal pollutants can adversely impact environmental quality and human health, particularly in regions that lack infrastructure for proper solid waste management. In one study, $\mathrm{Co}, \mathrm{Cu}, \mathrm{Ni}$, and $\mathrm{Pb}$ were identified as metals that leached out from LIB's under simulated landfill conditions and exceeded the regulatory limits [36].

\subsection{Recycling}

As with the reuse of the EV battery, effective recycling methods have the potential to immensely reduce the environmental impact and poor labor treatment involved with obtaining raw materials. It shifts the reliance on material from raw supplies to recovered supply which can be more controlled and regulated. Recycling methods have been and currently are undergoing research to maximize the recovery of the valuable metals and other raw materials. The most common processes used for the recycling EV batteries fall under two types of separation strategies: hydrometallurgy and pyrometallurgy.

Recycling is known to be an environmentally sound alternative to waste disposal. This is due to reuse of materials which prevents further environmental degradation through extraction of materials and transportation from the source to the manufacturer which is often across continents. Additionally, the availability for dumping spent batteries is becoming costly and increasingly restricted due to high likeliness of toxic metal leaching into soil [34, 37]. Aside from environmental responsibility, LBBs have many valuable metals which make recycling the battery the most economical option, the raw material value of 1 tone of batteries is valued at around $\$ 7,708$. Recycling these metals can save up to $50 \%$ of the cost to produce a new battery [35, 38] which makes developing the most efficient process for recycling desirable in the market as EVs continue to grow.

The preparation of the EV battery for recycling is consistent between both hydro and pyrometallurgical recycling methods. This includes the dismantling of casings, deactivation under high heat $\left(\sim 500^{\circ} \mathrm{C}\right)$, electrolyte volitization under the deactivation stage, as well as crushing and sieving processes to generate a metal electrode powder. Some external components such as pack housing, insulation, copper connects and other components can be reused up to 5 times (15 y) before recycling [36, 39]. The fine detailed methods of these recycling steps are highly variable 
Table 2. Weight Compositions of Metals in Electrode Powder from Wang, Vest and Friedrich [3]

\begin{tabular}{ccccccccc}
\hline Element & Li & Ni & Co & Mn & Cu & Al & Fe & C \\
\hline Composition (wt \%) & 3.95 & 17.9 & 4.15 & 15.2 & 0.95 & 1.14 & $<0.1$ & 36.6 \\
\hline
\end{tabular}

in terms of mechanical steps and heat addition, however, the electrode powder generated contains similar masses of electrode metals at generally constant percentages. Wang and Friedrich [26] summarized the average weight percentage of metals in the electrode power with the results summarized in Table 2.

The electrode powder is the input into the recycling processes which will be discussed. The efficiency of these processes is expected to increase in the near future as a large influx of EV batteries make pressures for economically viable extraction and efficient, large scale operations. Providing data for evaluating life cycle analysis (LCA) of these processes is imperative to the sustainable growth of this market. This can be achieved through continuous research of recycling processes as technological acceleration increases in order to ensure decisions are made that contribute to the lowest impact determined by LCA.

\subsubsection{Hydrometallurgy}

Hydrometallurgy is a chemical-based extraction method for electrode metal recovery in LIBs. The general process involves acid leaching of the in the presence of a reductant and the separation and recovery of the target metals. Common leaching agents include $\mathrm{H}_{2} \mathrm{SO}_{4}, \mathrm{HNO}_{3}$ or $\mathrm{HCl}$, reductants include $\mathrm{H}_{2} \mathrm{SO}_{3}, \mathrm{NH}_{2} \mathrm{OH}$ and $\mathrm{H}_{2} \mathrm{O}_{2}$ and further recovery using various solvent extraction methods and precipitation using solvents such as PC88A, Cyanex 272, DEHPA, D2EHPA and TOA and $\mathrm{NaOH}, \mathrm{NH}_{4} \mathrm{OH}$, citric acid and ammonium oxalate as precipitants [40, 41].

The metal extraction efficiencies and purities are a main advantage to using hydrometallurgical methods, Wang and Friedrich [40] found leaching efficiencies for a $\mathrm{LiCoO}_{2}$ cathode between 98.6\% - 99.9\% (Co, Ni, Cu, Li and graphite) using $2 \mathrm{~mol} / \mathrm{L}$ sulphuric, $4 \mathrm{~mol} / \mathrm{L}$ hydrochloric acid, $50 \mathrm{~g} / \mathrm{L}$ hydrogen peroxide and a 100 $\mathrm{g} / \mathrm{L}$ liquid to solid ratio after $120 \mathrm{~min}$ through the development of a product oriented process. The recycling efficiencies of the metals were found to be $98-100 \%, 97 \%, 94-99 \%$ and $60-95 \%$, 92-99\%, 95-98\%, and 48-64\% for graphite, copper powder, aluminum hydroxide, iron hydroxide, $\mathrm{Co}, \mathrm{Ni}$ and $\mathrm{Mn}$ salts and lithium carbonate, respectively. It was found that the graphite, $\mathrm{Co}, \mathrm{Ni}$ and Mn obtained was a high enough purity to be used in a new anode, graphite in industrial settlings is usually treated as waste currently. Numerous studies have confirmed these results on a laboratory scale including a paper by Zou [42] who developed a recycling process for a diverse mixture of cathode composition and achieved recovery rate near $100 \%$ for $\mathrm{Ni}, \mathrm{Mn}$ and Co using hydroxide precipitation and $80 \%$ for $\mathrm{Li}$ in the form of lithium carbonate. Additionally the cathode metals because of their high purity do not need to be separated by solvent extraction since these metals are combined for the manufacture of new cathodes. One suggestion of the study recommended further treatment of the aluminum and iron hydroxides to recover cobalt and nickel. A process by Chen and Zhou [41] who reduced leaching time down from $120 \mathrm{~min}$ to $90 \mathrm{~min}$ at the same leaching temperature using $2 \mathrm{~mol} / \mathrm{L}$ citric acid as a leachant and 2 vol.\% hydrogen peroxide achieving leaching efficiencies of about 97\%, 95\%, 94\% and $99 \%$ for $\mathrm{Ni}$, Co, $\mathrm{Mn}$ and $\mathrm{Li}$ for $\mathrm{LiNi}_{1 / 3} \mathrm{Co}_{1 / 3} \mathrm{Mn}_{1 / 3} \mathrm{O}_{2}$ cathodes. Dimethylgloxime and ammonium oxalate were used to precipitate nickel and cobalt, respectively, and oxalic acid was used scrub $\mathrm{Mn}$ and Li-ions from the precipitate. D2EHPA was used to recover $\mathrm{Mn}$ as $\mathrm{MnSO}_{4}$ and lastly the $\mathrm{Li}$ precipitated using $\mathrm{NaPO}_{4}$. Using these methods, metal recovery efficiencies of 95\%, 97\%, 98\% and $89 \%$ for $\mathrm{Ni}, \mathrm{Co}, \mathrm{Mn}$ and $\mathrm{Li}$, respectively, were achieved. No indication of graphite recovery was mentioned in the process.

The issue with hydrometallurgical methods is the amount of specific and often expensive chemicals needed for the recovery of metals. Additionally, the extraction methods are seen to produce large amounts of spending acid, acid gas, alkali, and solvents which require treatment [43]. There is a significant cost associated with treating secondary pollutions from hydrometallurgy, because these chemicals involved are generally toxic and range in composition, meaning treatment can be complicated and require specialized processes. The research conducted by Chen and Zhou [41] discussed above used an organic leaching acid in citric acid to perform their tests. Leaching with citric acid is desirable due to its low cost, natural degradation and absence of toxic gas production of $\mathrm{Cl}_{2}, \mathrm{NO}_{\mathrm{x}}$ and $\mathrm{SO}_{3}$ common with inorganic acids which are a threat to humans and the environment [41, 44]. Other organic acids such as succinic acid, DL-malic acid (L-and D-enantiomers), aspartic acid, ascorbic acid, oxalic acid, glycine and L-tartaric acid have proven as viable substitutes [45]. The process is a step in the right direction; however, solvent extraction is still commonly utilized to obtain high purity metals which elevate the quantity of secondary pollution from solvents and acid stripping. A study by $\mathrm{Li}$ et al. [46] compared metal recovery from $\mathrm{LiCoO}_{2}$ cathode batteries by leaching in citric, malic and aspartic acid from the recovery of lithium and cobalt. Recoveries of nearly $100 \%$ for $\mathrm{Li}$ and Co were achieved using $1.25 \mathrm{~mol} / \mathrm{L}$ citric and $1.5 \mathrm{~mol} / \mathrm{L}$ malic acid after $30 \mathrm{~min}$ and $40 \mathrm{~min}$ of leaching time, respectively at $90^{\circ} \mathrm{C}, \mathrm{H}_{2} \mathrm{O}_{2}$ at $1.0 \%$ and 2.0 vol.\%, respectively, and a S:L ratio of $20 \mathrm{~g} / \mathrm{L}$. Aspartic acid was proven to have inferior performance to citric and malic acid achieving only $60 \%$ recovery in $2 \mathrm{~h}$ under the same conditions, this is due to its weak acidity and low solubility in water. Through an environmental assessment of leachates, citric acid is derived from fermentation methods while the other most efficient organic leaching acids malic and aspartic acids are sourced from fossil derived butane [46]. This contributes to much lower energy intensity (FFC) per kilogram produced than the other acids. This shows citric acid to be the most environmentally and economically viable option and thus should be a priority for leachate selection. A study showed high recovery of $\mathrm{Li}$ and Co recoveries using $0.5 \mathrm{~mol} / \mathrm{L}$ citric acid leaching with $0.55 \mathrm{~mol} / \mathrm{L}$, a $\mathrm{S}: \mathrm{L}$ ratio of $25 \mathrm{~g} / \mathrm{L}$, temperature of $60^{\circ} \mathrm{C}$ and leaching time of $6 \mathrm{~h}$ [47]. The study also included $\mathrm{HCl}$ and $\mathrm{H}_{2} \mathrm{SO}_{4}$ as leachates, citric acid was seen to be superior in leaching performance compared to the inorganic acids. The process is also ultrasonic assisted which contributes to the high leaching efficiency through 
cavitation action. Similar methods have been developed by Chen et al. [48] using citric acid and tea waste (as a reductant) to achieve very high leaching efficiencies of $\mathrm{Li}$ and Co within $2 \%$ of citric acid $/ \mathrm{H}_{2} \mathrm{O}_{2}$ methods after $120 \mathrm{~min}$ at similar temperatures. The process also includes citric acid recycling through circulatory leaching with high efficiencies for Co and Li after 5 cycles. Additionally, the only by-products of the process under ideal conditions are water and $\mathrm{O}_{2}$. Optimal ultrasonic power was determined to be $90 \mathrm{~W}$, which led to $96.13 \%$ and $98.4 \%$ Co and Li recovery. This process achieves very high leaching efficiencies at low temperatures with the weak point being long leaching times. Additionally further extraction methods of the metals from the leaching solution were not included. Other sustainable methods using citric acid have been developed that uses circulatory leaching to reduce waste acid and use of oxalic acid to precipitate cobalt [44] in replacement of solvent extraction. Ultrasonic washing (NMP) was used and has been seen to be an effective method to wash and separate the cathode. NMP is a toxic solvent, but has the capacity to be recycled which can be applied to the recycling process. The circulatory leaching of acids using filter liquor was found to be effective at $35 \mathrm{~min}$ leaching times with leaching efficiencies of $98 \%$ and $90 \%$ for $\mathrm{Li}$ and Co, respectively. Optimal conditions included a leaching temperature of $90^{\circ} \mathrm{C}, \mathrm{L}: \mathrm{S}$ of $60 \mathrm{~mL} / \mathrm{g}$ and 0.9 vol.\% $\mathrm{H}_{2} \mathrm{O}_{2}$. High recoveries of Co (99.5\%) and $\mathrm{Li}(90.2 \%)$ were achieved through oxalic acid precipitation and sodium phosphate addition, respectively. Additional cycles of leaching reduce the leaching efficiency however recoveries above $80 \%$ can be achieved after 3 cycles. This process is effective at eliminating waste and coupled with high recoveries would make a successful eco-friendly process at the industrial level. The studies using citric acid as a leachate in literature however do not address the recovery of other metals during recovery such as $\mathrm{Ni}$ and $\mathrm{Mn}$ from the cathode. One study addresses this issue using $2 \mathrm{~mol} / \mathrm{L}$ L-tartaric acid with 4 vol.\% $\mathrm{H}_{2} \mathrm{O}_{2}$ at $70^{\circ} \mathrm{C}$ for 30 min to leach $\mathrm{Li}, \mathrm{Co}, \mathrm{Ni}$ and $\mathrm{Mn}$ from spent batteries [45]. High leaching efficiencies were found to be 99.31\%, 99.07\%, 98.64\%, and $99.31 \%$ for $\mathrm{Mn}, \mathrm{Li}$, Co and $\mathrm{Mn}$, respectively, with no recovery methods included in the study. This shows that organic acids can leach all cathode materials at high efficiencies.

LCA of rare earth element (REE) recovery in mining operations through solvent extraction have shown high environmental impact. Specifically, hydrochloric acid and sodium hydroxide were found to have high environmental impacts in various categories used for analysis and were utilized mainly in stripping processes [49] as would occur in hydrometallurgical solvent extraction. A novel process have demonstrated leaching times that have been brought down to $20 \mathrm{~min}$ at $70^{\circ} \mathrm{C}$ while maintaining comparable removal efficiencies using $1.25 \mathrm{~mol} / \mathrm{L}$ ascorbic acid as the leaching and reducing agent [37]. Leaching efficiencies peaked at $98.5 \%$ and $94.8 \%$ for $\mathrm{Li}$ and $\mathrm{Co}$, respectively. The method also uses NMP, but removes use of $\mathrm{H}_{2} \mathrm{O}_{2}$ in the leaching process. The shows promise for a low waste recycling method. This method is seen to be the most environmentally sustainable, while obtaining similar leaching and recovery efficiencies of other well established methods currently in use.

Other novel processes such as oxygen-free roasting and wet magnetic separation can successfully separate $\mathrm{Li}$, Co and graphite at recovery efficiency of $98.93 \%, 95.72 \%$ and $91.05 \%$, respectively, and without the creation of secondary pollution from chemical precipitation, solvent extraction or acid leaching [43]. The process is very long with $48 \mathrm{~h}$ of magnetic separation stirring times and required temperatures up to $1,400^{\circ} \mathrm{C}$ for roasting. Additionally, volatile organic compounds (VOCs) were emitted from the electrolyte at high temperatures which is the only pollutant from the process. With high efficiencies this process is desirable; however, more research needs to be conducted to increase process speed to compete with other alternatives.

Promising new research has been done into an ideal zero-waste recovery of metals from LIBs. Marinos and Mishra [50] proposed leaching electrode materials in stirred distilled water and using a floatation cell to wash particles of fine materials and float out plastics. The electrode powders are recovered by wet sieving and hydro cyclone separation while graphite is separated using pine oil. Lithium carbonate is recovered by introducing hydrochloric acid or carbon dioxide which is recycled in the process. The rest are separated using magnetic and eddy-current separation into mesh sizes. Little data is available on the purity, and currently further separation of metals is not part of the system. However, the research is only a few years old and has potential to be a novel, environmentally friendly process with close to $100 \% \mathrm{Li}$ recovery at specific leaching times.

\subsubsection{Pyrometallurgy}

Pyrometallurgy involves separation of materials through thermal processes, rather than chemical processes as hydrometallurgy does. Through varying degrees of heating of the material, thermal energy initiates reactions to transform the material. The extent and type of changes to the material depends on the severity of the heat applied. Using high temperatures for this process can cause the batteries to be smelted, which produces three products: metallic fraction, slag, and gasses. This recycling technique is often used in industrial furnaces, in which metalliferous materials and metals are produced or cleaned [51]. The main pyrometallurgical methods used for the recovery of metals from electric waste in general are smelting, combustion, pyrolysis, and molten salt processes (such as calcination) [52]. However, for the purpose of LIBs specifically, heat treatment through calcination and pyrolysis is very common.

Calcination thermally decomposes material by use of relatively mild heat, but can rise up to as high as $1,500^{\circ} \mathrm{C}$ [53]. Usually inorganic reactants are used in calcination. It is a process that is commonly used in the manufacturing of cement, and with material recovery often produces a slag byproduct which can be sold to construction companies for use in cement. The reactions involved are mostly internal reactions that only involve the material itself [51].

Pyrolysis is the thermal decomposition of organic material at elevated temperatures in the absence of oxygen. This causes irreversible reactions that result in the simultaneous change of chemical composition and physical phase of the materials. This leads to the formation of low-molecular byproducts and char by thermal decomposition reactions between $450-1,100^{\circ} \mathrm{C}$ [52]. These byproducts are often valuable for use as fuel, while the char can contain much of the valuable metals in the battery. 
Research completed in the ELIBMA project was done on a process involving calcination in conjunction with pyrolysis, which involved the addition of reducing agents into an oxygen deficient environment for burning at temperatures up to $700^{\circ} \mathrm{C}$. The metallic fraction produced contains metals that have low affinity to oxygen and is further refined for the separation of the metals. This mixture is also reduced to balance out the oxidation that occurred during the calcination/pyrolysis stage. This is usually achieved by adding a relatively cheap reducing agent such as coke. The slag produced is a stony mixture of materials that can be sold and used for construction and the production of cement. Finally, the gas fraction that is produced is to be filtered before being released into the atmosphere due to its harmful composition, containing volatile decomposition products and volatile metals such as $\mathrm{Hg}$ and $\mathrm{Zn}$ [52]. Because pyrometallurgic processes involve immediate burning of material at high temperatures, they are considered fast, and easy to handle [51].

As mentioned above, the cathode and electrode compositions vary greatly in Li-ion EV batteries. One of the major advantage to pyrometallurgy as a material recovery technique is its ability to be effective for a large array for electrode chemistries without altering the method significantly [35]. Additionally, pyrometallurgy consumes about half the water that is consumed during the hydrometallurgy process [35].

Although the metallic smelt produced recovers many of the metals and the stony slag generated can also be applied for secondary uses, the harmful gas fraction poses an environmental risk factor to this process.

A study by Hendrickson et al [54] shows that a 6-56\% energy reduction and 23\% GHG emission reduction can be expected for pyrometalurgical methods for recycling when compared to virgin production or raw material for EV battery production. This is based off of modeling only two dismantling facilities in the state of California which was shown to be most economically feasible [54]. The study also explains that there are challenges with chemistries such as LMO batteries, as the active materials are relatively cheap and recycling is not considered economical. Additionally, scaling up pyrometallurgical recycling methods can pose serious human health risks in nearby areas. The study shows that $\mathrm{NO}_{\mathrm{x}}$ production was $96 \%$ from the pyrometallurgy facility, while health risks associated with other pollutants such as PM, $\mathrm{SO}_{2}$, and VOCs were produced mostly from the depleted EV batteries transportation, marking 99\% of the total PM produced. However, a negligible amount of $\mathrm{SO}_{2}$ was generated during the recycling process while transportation and energy generation processes made up 99\% of $\mathrm{SO}_{2}$ production [54].

LCA was made to show the outputs of EV battery production from pyrometallurgy and hydrometallurgy are compared to that of raw material production [35]. The result showed pyrometallurgy exceeding production from raw materials in electricity consumption and the release of $\mathrm{PM}_{2.5}$ and VOCs. The electricity consumption and $\mathrm{PM}_{2.5}$ production was shown to exceed double that of hydrometallurgy [35].

Any pyrometallurgic process involving the heating of the materials until decomposition can result in similar, harmful byproducts that must be considered. However, due to the ease of handling
Table 3. Pyrometallurgy, Hydrometallurgy Summary Table

\begin{tabular}{ll}
\hline Pyrometallurgy & Hydrometallurgy \\
\hline • Physical (thermal) process & • Chemical process \\
• Dry process & • Wet process \\
• Harmful gas fraction in & • Byproducts: Minimal \\
byproduct & • High material selectivity and \\
- High metal recovery, & efficiency \\
Low material selectivity & - Relatively costly \\
- Inexpensive & - Time consuming \\
• Fast process & - Low energy input \\
• High energy input & - Toxic chemicals in solvent \\
- No requirement for toxic & reactions \\
chemicals & \\
\hline
\end{tabular}

and low cost involved with pyrometallurgy for metal recovery from LIBs, it is currently the method implemented by most battery recycling companies worldwide (Table 3).

Based on the characteristics compared above, hydrometallurgic processes for LIB material recovery are very effective. Currently, the more common method implemented for metal recovery is pyrometallurgy, but as research continues, and LIB are recycled on a larger scale, the economic feasibility of hydrometallurgy is expected to decrease. Based on its lower environmental impact as well as higher recovery and selectivity rates, hydrometallurgical methods are expected to become much more widely implemented.

\section{Umicore Tracking}

Umicore is one of the world's leading heavy metal recovery companies that specialize in recycling almost all readily available battery types [55]. They are an international company, with facilities spread across Europe, Asia and North America. The facility of interest however, is situated in Hoboken, Belgium, where Umicore has established its biggest, most sophisticated battery recycling plant to date [56]. This facility can safely recover 17 different types of metals found in batteries and can process a total of 500,000 tons of batteries per year. The majority of the batteries currently being processed are lead-acid or other variations of NiMH. Due to the aforementioned struggles involved with recycling LIBs, only 7,000 tons of LIBs are able to be processed per year. Umicore is aware of this shortcoming and has developed its very own recycling process, which is more efficient and produces far less emissions than other leading LIB recycling techniques.

\subsection{Patented Recovery Process}

Umicore has a patented "internationally recognized recycling process" which claims to utilize a combination of pyrometallurgy and a state-of-the-art hydrometallurgical process in order to recycle all sizes and types of LIB [57]. With the future in mind, Umicore designed its facility to be able to process large quantities of metal based waste streams at once, in anticipation of the Li-ion becoming more popular with the rise of EV use.

The process begins with the pyrometallurgic phase. Umicore uses an Ultra High Temperature (UHT) pyrometallurgic recycling 
technique, which varies from traditional pyrometallurgical methods through use of temperatures that exceed $3,000^{\circ} \mathrm{C}$ rather than typical $700-1,500^{\circ} \mathrm{C}$ temperatures. Umicore's pyrometallurgical method then follows common practices, by reducing the spent batteries down into three fractions. The most important fraction consists of a metal alloy which contains the various desired heavy metals including $\mathrm{Co}, \mathrm{Ni}$ and $\mathrm{Cu}$. This alloy will be further manipulated to improve purity later on in the recycling process. The second fraction consists of a slag type product which contains the lithium which has been extracted from the batteries. The final fraction produced is a gas stream, which is subjected to dust collection and further filtering to remove pollutants, thus it is released back into the atmosphere as clean air.

Through use of their UHT variation of the pyrometallurgic recycling technique, Umicore claims to reap the following benefits [57]:

- Spent batteries can be fed directly into the smelter, which requires no costly pre-treatment

- Higher heavy metal recovery rates achieved from the metal alloy waste fraction

- $\mathrm{CO}_{2}$ emissions and energy consumption are mitigated by using energy that is already present inside the spent battery components

The second and final step of Umicore's recycling process is the hydrometallurgical portion. Here, the metal alloy waste fraction obtained through the previously completed pyrometallurgic process is further processed to increase the purity of the entrapped heavy metals. Umicore's hydrometallurgical process follows the same general procedure as most other companies. The edge that Umicore has over other companies is that the final heavy metals are converted back into active cathode materials, which are then sold directly to LIB production companies [57].

Unfortunately, under current circumstances, the cost to remove the lithium from the slag fraction can cost up to 5 times more than it would to purchase new, raw material. Due to the lack of a profitable recycling method with current technology, Umicore sells their slag fraction to construction companies, where it can be used as a concrete aggregate, among other applications [58]

Although Umicore has not yet developed a completely closed loop LIB recycling process, this is their ultimate goal. They are confident in their ability to further technology and to be the world's first company able to perform such a feat.

\section{Conclusions}

The drastic growth of EVs and LIBs, increase the necessity of LIBs proper handling, therefore will become a highly valued industry which is currently has many areas for improvement. The $\mathrm{LIB}$ anodes need to undergo significant development in the coming years. One of the biggest shortcomings in LIBs is their ability to hold capacity and further innovation in the components of the battery, for instance the anode will allow them to be increasingly competitive against the conventional combustion engine. The current designs of LIBs implemented in EVs are not sufficient to be competitive with traditional combustion vehicles, and further development of the batteries should facilitate long term growth in the market. Interestingly, silicon based anodes have the potential to increase the capacity of the battery tenfold relative to the conventional LIB anode. Companies such as Tesla have begun implementing silicon into the anode of their EV batteries as a means of increasing the capacity of these batteries. Consequently, the batteries of today will undergo drastic changes in material properties that will increase their performance.

While battery development continues at a fast pace, material recovery remains significantly underdeveloped. Currently, the prevalent recycling method for LIBs is pyrometallurgy. However, it is associated with high energy requirements, adverse environmental impacts, and low metal recovery and selectivity reducing the efficacy of this recycling technology. The other method discussed in this article, i.e., hydrometallurgy, probably presents a much more promising alternative, based on extremely high metal recovery and selectivity and lower emissions as well as lower production cost. It is clear that hydrometallurgy will eventually become the most sustainable and cost effective recovery method. The use of citric acid as the leaching agent appears to be the most viable acid for metal recovery of EV batteries moving forward. Citric acid is an organic acid that is environmentally sustainable and cheaper to produce compared to other alternatives. Furthermore, it is less toxic relative to many other inorganic leaching agents and requires no additional treatment before disposal. We recommend including citric acid as a leaching agent to achieve the most sustainable method in hydrometallurgic recycling. Finally, it is recommended that Canada and North America as a whole implement the steps currently being taken by many European countries in term of collection, recycling and promotion of EV's through legislation. The growth of the electric vehicle batteries in the near future is inevitable, and the sooner we prepare, the more we will have to gain through enhanced environmental protection, benefiting economically, and expending industries sustainably.

\section{References}

1. Poole I. Lithium ion battery advantages and disadvantages. [Internet]. Radio-electronics. [cited 29 November 2017]. Available from: http://www.radio-electronics.com/info/powermanagement/battery-technology/lithium-ion-battery-advantagesdisadvantages.php.

2. Eisenstein PA. These countries want to ban all vehicles that run on gas or diesel. [Internet]. NBC News. [cited 29 November 2017]. Available from: https://www.nbcnews.com/business/ autos/these-countries-want-ban-all-vehicles-run-gas-or-diesel-n781431.

3. Chestney N. Number of electric vehicles on the roads reaches 2 million. [Internet]. Reuters. [cited 29 November 2017]. Available from: https://www.reuters.com/article/us-autos-electric/ number-of-electric-vehicles-on-roads-reaches-two-million-iea-idU SKBN18Y0XM.

4. Gu H, Liu Z, Qing Q. Optimal electric vehicle production strategy under subsidy and battery recycling. Energ. Policy 2017;109:579-589.

5. Berckmans G, Messagie M, Smekens J, Omar N, Vanhaverbeke 
L, Mierlo JV. Cost projection of state of the art lithium-ion. [Internet]. Energies [cited 29 November 2017]. Available from: https://www.mdpi.com/1996-1073/10/9/1314.

6. International Energy Agency. Global EV Outlook 2017 Two Million and Counting. Global EV outlook 2017 two million and counting [Internet]. Available from: https://www.iea. org/publications/freepublications/publication/GlobalEVOutlook 2017.pdf.

7. McKinsey and Company. Electrifying insights: How automakers can drive electrified vehicle sales and profitability. Advanced Industries; 2017. p. 1-26.

8. Deng D. Li-ion batteries: Basics, progress, and challenges. Energ. Sci. Eng. 2015;3:385-497.

9. Nitta N, Wu F, Lee JT, Yushin G. Li-ion battery materials: Present and future. Mater. Today 2015;18:252-264.

10. Takami N, Inagaki H, Tatebayashi Y, Saruwatari H, Honda K, Egusa S. High-power and long-life lithium-ion batteries using lithium titanium oxide anode for automotive and stationary power applications. J. Power Sources 2013;244:469-475.

11. Charged Electric Vehicles Magazine. Tesla tweaks its battery chemistry: A closer look at silicon anode development. [cited 30 November 2017]. Available from: https://chargedevs.com/ features/tesla-tweaks-its-battery-chemistry-a-closer-look-atsilicon-anode-development/.

12. Zuo X, Zhu J, Muller-Buschbaum P, Cheng YJ. Silicon based lithium-ion battery anodes: A chronicle perspective review. Nano Energ. 2017;31:113-143.

13. Bareno J, Shkrob I, Gilbert JA, Klett M, Abraham DP. Capacity fade and its mitigation in Li-ion cells with silicon-graphite. J. Phys. Chem. C 2017;121:20640-20649.

14. Jenden J, Donev J, Stenhouse K. Energy density vs power density. In: energy Education, Calgary, Univ. of Calgary. [cited 30 September 2018] Available from: https://energyeducation. ca/encyclopedia/Energy_density_vs_power_density.

15. Dunn JB, Gaines L, Kelly JC, James C, Gallagher KG. The significance of Li-ion batteries in electric vehicle life-cycle energy and emissions and recycling's role in its reduction. Energ. Environ. Sci. 2015;8:158-168.

16. Danie C. Materials and processing for lithium-ion batteries. TMS; c2008 [cited 01 June 2018]. Available from: http:// www.tms.org/pubs/journals/JOM/0809/daniel-0809.html.

17. Perea A, Dontigny M, Zaghib K. Safety of solid-state Li metal battery: Solid polymer versus liquid electrolyte. Elsevier; c2017 [cited 6 Feb 2018]. Available from: https://www. sciencedirect.com/science/article/pii/S0378775317307024.

18. Solid-state electrolyte with lithium-ion conductivities comparable to liquid electrolytes. The henryk niewodniczanski institute of nuclear physics polish academy of sciences. [cited 06 Feb 2018]. Available from: https://phys.org/news/201709-solid-state-electrolyte-lithium-ion-liquid-electrolytes. html.

19. Mikolajczak C, Khan M, White K, Thomas R. Lithium-ion batteries hazard and use assessment [Internet]. The fire protection research foundation; c2011 [cited 06 February 2018]. Available from: http://www.prba.org/wp-content/uploads/Exponent_ Report_for_NFPA_-_20111.pdf.

20. Frost-Sullivan. Solid-state electrolytes - Next-generation safer alternative in Li-ion batteries. [cited 02 June 2018]. Available from: https://ww2.frost.com/frost-perspectives/solid-state-electrolytes- next-generation-safer-alternative-li-ion-batteries/.

21. Targray. Battery separators: PE and PP foam battery seperators for lithium-ion battery manufacturers and R\&D [Internet]. [cited 02 August 2018]. Available from: https://www.targray. com/li-ion-battery/separators.

22. Weber CJ, Geiger S, Falusi S, Roth M. Material review of li ion battery separators [Internet]. American Institute of Physics; c2014 [cited 02 August 2018]. Available from: http://aip.scitation. org/doi/pdf/10.1063/1.4878480.

23. BU-306. What is the function of the separator? [Internet]. Battery Univ.; c2017 [cited 02 September 2018]. Available from: http:// batteryuniversity.com/learn/article/bu_306_battery_ separators.

24. BU-304a. Safety concerns with Li-ion. Battery Univ.; c2018 [cited 02 September 2018]. Available from: http://batteryuniversity. com/learn/article/safety_concerns_with_li_ion.

25. Fehrenbacher K. A lithium gamble that could win big for Tesla. Fourtune, c2016 [cited 30 November 2017]. Available from: http://fortune.com/2016/03/29/lithium-tesla-mine-nevada/.

26. Wang H, Vest M, Friedrich B. Hydrometallurgical processing of Li-ion battery scrap from electric vehicles. In: 6th European Metallurgical Conference (EMC) Aachen, Germany; 2011.

27. Lambert F. Breakdown of raw materials in Tesla's batteries and possible bottlenecks. Electrek; c2016 [cited 15 November 2017]. Available from: https://electrek.co/2016/11/01/breakdown-raw-materials-tesla-batteries-possible-bottleneck/.

28. Mmereki D, Baldwin A, Hong L, Li B. The management of hazardous waste in developing. In: Management of Hazardous Wastes. Published by Intech; 2016.

29. Bipower Corp. Lithium battery disposal guidelines. [cited 12 March 2017]. Available from: http://www.bipowerusa.com/ documents/disposal.asp.

30. Standridge CR, Corneal L. Remanufacturing, repurposing and recycling of post-vehicle-application lithium-ion batteries. Mineta National Transit Research Consortium; c2014 [cited 29 November 2017]. Available from: http://transweb.sjsu. edu/PDFs/research/1137-post-vehicle-Li-Ion-recycling.pdf.

31. Liao Q, Mu M, Zhao S, et al. Performance assessment and classification of retired lithium ion battery from electric vehicles for energy storage. Int. J. Hydrogen Energ. 2017;42: 18817-18823.

32. Heymans C, Walker SB, Young SB, Fowler M. Economic analysis of second use electric vehicle batteries for residential energy storage and load-levelling. Energ. Policy 2014;71:22-30.

33. Tong S, Fung T, Klein MP, Weisbach DA, Park JW. Demonstration of reusing electric vehicle battery for solar energy storage and demand side management. J. Energ. Storage 2017;11:200-210

34. Ficicchia C. After-market applications for depreciated EV batteries in the NY metro region. A feasibility and market research study, empire clean cities. Nysera, New York; 2016; p. 75

35. Hendrickon TP, Sathre R, Kavvada O, Scown CD. Plug-in electric Vehicle battery recycling scale-up strategies for California (2015-2050). In: Energy Research and Development Division, Lawrence Berkeley National Laboratory. Sacramento: 
California Energy Comisssion; 2016.

36. Kang DHP, Chen, M, Ogunseitan OA. Potential environmental and human health impacts of rechargeable lithium batteries in electronic waste. Environ. Sci. Technol. 2013;47:5495-5503.

37. Li L, Lu J, Ren Y, et al. Ascorbic-acid-assisted recovery of cobalt and lithium from spent Li-ion batteries. J. Power Sources 2012;218:21-27.

38. Ataur R, Afroz R. Lithium battery recycling management and policy. Int. J. Energ. Technol. Policy 2017;13:278-291.

39. Olofsson Y, Romare M. Life cycle assessment of lithium-ion batteries for plug-in hybrid buses. [dissertation] Gothenburg, Sweden: Chalmers Univ. of Technology; 2013.

40. Wang H, Friedrich B. Development of a highly efficient hydrometallurgical recycling process for automotive Li-ion batteries. J. Sust. Metallurgy 2015;1:168-178.

41. Chen X, Zhou T. Hydrometallurgical process for the recovery of metal values from spent lithium-ion batteries in citric acid media. Waste Manage. Res. 2014;32:1083-1093.

42. Zou H. Development of a recycling process for li-ion batteries [dissertation]. Worcester Polytechnic Institute, Worcester; 2012.

43. Li J, Wang G, Xu Z. Environmentally-friendly oxygen-free roasting/wet magnetic separation technology for in situ recycling cobalt, lithium carbonate and graphite from spent $\mathrm{LiCoO}_{2}$ /graphite lithium batteries. J. Hazard. Mater. 2016;302: 97-104.

44. Fan B, Chen X. Zhou T, Zhang J, Xu B. A sustainable process for the recovery of valuable metals from spent lithium-ion batteries. Waste Manage. Res. 2016;34:474-481.

45. He LP, Sun SY, Mu YY, Song XF, Yu JG. Recovery of lithium, nickel, cobalt, and manganese from spent lithium-ion batteries using Ltartaric acid as a leachant. ASC Sust. Chem. Eng. 2017;5:714-721.

46. Li L, Dunn JB, Zhang XX, et al. Recovery of metals from spent lithium-ion batteries with organic acids as leaching reagents and environmental assessment. J. Power Sources 2013;223:180-189.

47. Li L, Zhai L, Zhang X, et al. Recovery of valuable metals from spent lithium-ion batteries by ultrasonic-assisted leaching process. J. Power Sources 2014;262:380-385.
48. Chen X, Luo C, Zhang J, Kong J, Zhou T. Sustainable recovery of metals from spent Lithium-ion batteries: A green process. ASC Sust. Chem. Eng. 2015;3:3104-3113.

49. Vahidi E, Zhao F. Environmental life cycle assessment on the separation of rare earth oxides through solvent extraction. J. Environ. Manage. 2017;203:255-263.

50. Marinos D, Mishra B. An Approach to processing of lithium-ion batteries for the zero-waste recovery of materials. J. Sust. Metall. 2015;1:263-274.

51. European Commission. European li-ion battery advanced manufacturing for electric vehicles [Internet]. Elibama; [cited 29 November 2017]. Available from: https:// elibama.files. wordpress.com/2014/10/v-d-batteries-recycling1.pdf.

52. Changnes A, Cote G, Ekberg C, Nilsson M, Retegan T. WEEE recycling. Research, development, and policies. 1st ed. Elsevier; 2016. p. 234.

53. Fink JK. Pyrolysis and combustion of polymer wastes in combination with metallurgical processes and the cement industry. J. Anal. Appl. Pyrol. 1999;51:239-252.

54. Hendrickson TP, Kavvada O, Shah N, Sathre R, Scown CD. Life-cycle implications and supply chain logistics of electric vehicle battery recycling in California. Environ. Res. Lett. 2015;10:014011.

55. Molotova E. Catalysts and metal recycling. Berenberg [Internet]. c2013 [cited 30 November 2017]. Available from: https:/www. berenberg.de/fileadmin/user_upload/berenberg2013/ 02_Investment_Banking/Equity_Research/2013_07_16_Catal ysts_and_metal_Chemicals.pdf.

56. Umicore. A major investment tackles a global challenge. [cited 30 November 2017]. Available from: http://www.umicore. com/en/cases/hoboken/.

57. Umicore. Our recycling process. [cited 29 November 2017]. Available from: http://pmr.umicore.com/en/batteries/our-recycling-process.

58. Kumar A. The lithium ion battery recycling challenge [Internet]. Waste Management World. c2011. [cited 30 November 2017]. Available from: https:/waste-management-world.com/a/1-the- lithium-battery-recycling-challenge. 